\title{
EDITORIAL
}

\section{ACCESO Y GRADUACIÓN EN LA FORMACIÓN PROFESIONAL UNIVERSITARIA}

Access and graduation in university professional training

$\underbrace{\mathrm{d}}$ el mundo actual, hay más estudiantes universitarios que en cualquier otra época de la historia moderna de la humanidad, y la tendencia es que el número continúe creciendo en el futuro. El acceso masivo a la formación universitaria también es una realidad en nuestro país. El número de postulantes a la universidad se ha duplicado en los últimos diez años; así, en el 2005 se registraron 411000 postulantes y en el 2015 fueron 815000 , y se proyecta que vuelva a duplicarse en los próximos diez años.

Gracias a políticas de fomento de la inversión privada en la educación, en la que se incluye a la educación universitaria, el sistema universitario nacional se compone de universidades públicas, universidades privadas asociativas y universidades privadas societarias-i.e. universidades empresas. En la actualidad, las universidades privadas societarias son las que cuentan con el mayor número de estudiantes universitarios matriculados en nuestro país, pero esto no fue siempre así. En el 2005, el $50 \%$ de estudiantes pertenecía a la universidad pública y solo el $12,7 \%$ a la privada societaria. Diez años después, de 1'361 000 estudiantes universitarios, el 22,5\% pertenecía a universidades públicas y el $38,5 \%$ a universidades privadas societarias, lo que evidencia la magnitud de este cambio demográfico de estudiantes universitarios en la que las universidades empresas ocupan un espacio importante en la formación profesional en nuestro país.
El mayor acceso a la educación universitaria privada no conlleva necesariamente a una mayor tasa de graduación de los estudiantes ni garantiza la calidad de la educación universitaria. A pesar de las limitaciones de la universidad pública, el $60 \%$ de los estudiantes culmina sus estudios y se gradúa; mientras que solo el 33\% lo logra en la universidad privada, considerando seis años de estudios de la carrera universitaria. Estas cifras nos sugieren que a pesar del acceso extendido a la educación universitaria privada, del total de estudiantes que inician estudios solo lo logran culminar satisfactoriamente alrededor de la tercera parte, y los dos tercios restantes lo hacen en mayor tiempo o no lo hacen nunca. Este es un indicativo que no se está cumpliendo el objetivo principal de la educación universitaria: el profesional; es decir, la persona que culminado sus estudios de carrera universitaria se ha graduado, ha obtenido la licencia para ejercer la profesión y se ha insertardo en la actividad laboral profesional.

Hay universidades en que más del $60 \%$ de las cohortes de estudiantes matriculados no culmina sus carreras en los tiempos programados. Sin generalizaciones erróneas, este es un problema de la calidad de la educación universitaria que afecta tanto a la universidad pública y privada en el país, pero es en la universidad empresarial donde este problema es significativamente mayor. Muchos factores se conjugan en esta situación. Entre ellos, la universidad privada societaria, para recuperar 
la inversión y ser rentable en su propuesta de negocios, requiere de cohortes numerosas de matriculados. Por ello admite a la mayoría de sus postulantes sin importar si son capaces de culminar sus estudios o no; así, el $83 \%$ de los postulantes es admitido en la universidad privada societaria y el $18 \%$ en la universidad pública. Esto último equivale a dos admitidos de cada diez postulantes, una tasa adecuada de selección, mientras que en la privada societaria casi todos los que postulan son admitidos.

La universidad es una vieja institución que ha devenido en la encargada del saber, la praxis y la legis de la formación profesional de sus ciudadanos. Del saber porque para ejercer una profesión se requiere del conocimiento del arte de una disciplina, de la praxis por las destrezas que se debe tener en el ejercicio de la profesión y de la legis por los estándares éticos y legales de la conducta profesional. Este rol formativo de la universidad es importante porque en los profesionales recae la responsabilidad del ejercicio de disciplinas que contribuyen al bienestar y al desarrollo de una sociedad, como son la salud, el derecho, la economía, la ingeniería, la educación, entre otras. No puede haber una sociedad que progresa sin bien informados, diestros y correctos profesionales.
La institución universitaria a nivel global ha sido impactada por la masiva demanda de formación profesional, por la movilidad internacional de estudiantes, la globalidad de la ciencia y por las tecnologías de la información que permiten el acceso a sus programas desde cualquier lugar del mundo. La universidad se ha convertido en una comunidad extensa dedicada al aprendizaje, la educación y la investigación, cada vez más abierta gracias al uso de las linguas francas: el inglés, las ciencias, los códigos de computación. Pero en nuestro país, en esta comunidad muchos son los que inician estudios pero menos los que los culminan en el periodo de duración de los estudios de la carrera. ¿Cuánto es el costo económico y social de ofrecer un servicio formativo a jóvenes que no pueden o no deben enrolarse en los estudios universitarios? No lo sabemos, pero seguramente es cuantioso. Se puede inferir que la deserción de los estudios universitarios es también alta. La baja graduación universitaria es uno de los problemas de la educación superior en el país, que nuestra sociedad debe considerar y afrontar.

Los invito a reflexionar sobre las diversas aristas del tema y sus posible soluciones.

\section{Jasé Espinaza Balilón}

